\title{
Design of Modular Peptide Surfactants and their
}

\section{Surface Activity}

Hao-Fei Wang ${ }^{\dagger, 1}$, David Wibowo ${ }^{\dagger, 1}$, Zhengzhong Shao ${ }^{\ddagger}$, Anton P. J. Middelberg ${ }^{\dagger}$, and ChunXia Zhao ${ }^{\dagger *}$

${ }^{\dagger}$ Australian Institute for Bioengineering and Nanotechnology, The University of Queensland, St Lucia QLD 4072, Australia.

${ }^{\ddagger}$ State Key Laboratory of Molecular Engineering of Polymers, Laboratory of Advanced Materials and Department of Macromolecular Science, Fudan University, Shanghai 200433, China.

${ }^{1}$ H.F.W. and D.W. contributed equally to this work. 


\section{KEYWORDS}

Interface; Nanoemulsion; Emulsion stability; Biosurfactant; Designer peptides 


\section{ABSTRACT}

Designed peptide surfactants offer a number of advanced properties over conventional petrochemical surfactants, including biocompatibility, sustainability, and tailorability of the chemical and physical properties through peptide design. Their biocompatibility and degradability make them attractive for various applications, particularly for food and pharmaceutical applications. In this work, two new peptide surfactants derived from an amphiphilic peptide surfactant (AM1) were designed (AM-S and $\mathrm{C}_{8}$-AM) to better understand links between structure, interfacial activity and emulsification. Based on AM1, which has an interfacial $\alpha$-helical structure, AM-S and $\mathrm{C}_{8}$-AM were designed to have two modules, that is, the $\alpha$-helical AM1 module and an additional hydrophobic moiety to provide for better anchoring at the oil-water interface. Both AM-S and $\mathrm{C}_{8}$-AM at low bulk concentration of 20 $\mu \mathrm{M}$ were able to adsorb rapidly at oil-water interface, and reduced interfacial tension to equilibrium values of $17.0 \mathrm{mN} / \mathrm{m}$ and $8.4 \mathrm{mN} / \mathrm{m}$ within $400 \mathrm{~s}$, respectively. Their relatively quick adsorption kinetics allowed the formation of nanoemulsions with smaller droplet sizes and narrower size distribution. AM-S and $\mathrm{C}_{8}-\mathrm{AM}$ at $800 \mu \mathrm{M}$ bulk concentration could make nanoemulsions of average diameter $180 \mathrm{~nm}$ and $147 \mathrm{~nm}$, respectively, by simple sonication. With respect to the long-term stability, a minimum peptide concentration of $400 \mu \mathrm{M}$ for AMS and a lower concentration of $100 \mu \mathrm{M}$ for $\mathrm{C}_{8}$-AM were demonstrated to effectively stabilize nanoemulsions over three weeks. Compared to AM1, the AM-S nanoemulsion retained its stimuli-responsive function triggered by metal ions, whereas the $\mathrm{C}_{8}$-AM nanoemulsions did not respond to the stimuli as efficiently as AM-S because of the strong anchoring ability of the hydrophobic C8 module. The two-module design of AM-S and $\mathrm{C}_{8}-\mathrm{AM}$ represents a new strategy in tuning the surface activity of peptide surfactants, offering useful information and guidance of future designs. 


\section{INTRODUCTION}

Designer peptides have been explored as building blocks for making nanobiomaterials with many attractive properties. Various peptides can be designed either by modifying existing sequences to add extra functions or by creating new sequences to have completely new functions for a wide variety of applications ranging from water treatment, ${ }^{1}$ drug delivery, ${ }^{2}$ BD tissue culture, ${ }^{3-4}$ to membrane protein stabilization, ${ }^{5}$ antimicrobial ${ }^{6}$ and antitumor drugs..$^{7-8}$ Peptides are generally amphiphilic, possessing distinct hydrophilic and hydrophobic moieties. Designer peptides with either $\alpha$-helical or $\beta$-sheet structures have been proposed as useful building blocks for making new materials through self-assembly. ${ }^{9-10}$ Zhang et al. discovered a repetitive peptide, EAK-II (AEAEAKAKAEAEAKAK), which could form extended and ordered $\beta$-structure fibers and gels. ${ }^{11}$ The group further developed similar peptides, EAK-I, RADA 16-I and RADA 16-II which were able to self-assemble into networks of hydrogelated nanofibers as scaffolds for cell attachment and tissue culture. ${ }^{12}$ Peptides that favor $\alpha$-helical structures have also been designed to self-assemble into nanotubes. ${ }^{13-14}$ Baumann et al. studied the self-assembly of cationic-head surfactant-like eight-residue peptides, and found that short peptides with a $\beta$-sheet secondary structure tend to form ribbon-like assemblies, while peptides with random-coil and $\alpha$-helical secondary structures self-assemble into rods. ${ }^{15}$

Peptides have also been designed as biosurfactants because of their intrinsic amphiphilic properties. Peptide surfactants are commonly designed with a hydrophilic head consisting of charged polar amino acids and a hydrophobic tail containing amino acids with hydrophobic side chains to replicate the structure of conventional surfactants. Matsumoto et al designed a class of short peptide surfactants (i.e. Ac- $\mathrm{I}_{6} \mathrm{~K}_{2}-\mathrm{CONH}_{2}$, Ac- $\mathrm{A}_{6} \mathrm{~K}-\mathrm{CONH} 2, \mathrm{Ac}_{2} \mathrm{~V}_{6} \mathrm{~K}_{2}-\mathrm{CONH}_{2}$, and $\mathrm{Ac}-\mathrm{V}_{6} \mathrm{R}_{2}-\mathrm{CONH}_{2}$ ) with repeating hydrophobic residues and discovered their good performance in stabilizing membrane protein Photosystem-I. ${ }^{16}$ Similarly, Zhao et al studied a 
class of designer peptides consisting of seven amino acids with hydrophilic head and hydrophobic tails (i.e. Ac- $\mathrm{A}_{6} \mathrm{D}-\mathrm{COOH}, \mathrm{Ac}-\mathrm{A}_{6} \mathrm{~K}-\mathrm{COOH}$ ). These peptides have been found to effectively stabilize a G protein-coupled receptor under thermal denaturation conditions. ${ }^{17}$ On the other hand, peptides can also be designed to have an $\alpha$-helical structure with distinct hydrophobic and hydrophilic faces, where these are emergent when the peptide folds. Their facially amphiphilic conformation allows their quick adsorption on the interface by minimizing self-assembly in bulk; this rapid adsorption from non-micellar bulk structures facilitates emulsification. Such designer peptides have advantages over traditional chemical surfactants including biocompatibility and biodegradability, which make them desirable for making emulsions for biomedical applications. ${ }^{18-19}$

Previously, the peptide surfactant AM1 (Ac-MKQLADS LHQLARQ VSRLEHA-CONH 2 ) was designed based on a natural amphipathic peptide Lac21 (MKQLADS LMQLARQ VSRLESA $)^{20}$ with histidine replacing methionine and serine at positions 9 and 20. AM1 consists of a seven-residue repeating motif abcdefg, in which the $a$ and $d$ residues having hydrophobic side chains, while the remaining sites are predominantly hydrophilic. This alternate three- and four-residue spacing of hydrophobic moieties facilitates the formation of $\alpha$-helical (3.6 residue per turn) structures during peptide adsorption at the interface, forming distinct hydrophobic and hydrophilic faces that orientate toward oil phase and bulk aqueous phase, respectively. The incorporation of two metal-binding histidine $(\mathrm{H})$ residues within AM1 mediates intermolecular cross-linking via metal ions (i.e., $\mathrm{Zn}^{2+}, \mathrm{Co}^{2+}$, and $\mathrm{Ni}^{2+}$ ), ${ }^{21}$ forming interfacial peptide networks capable of stabilizing oil-water interfaces. ${ }^{20,22-24}$ Our previous studies demonstrated the excellent surface activity of AM1, the stimuli-responsive property of the interfacial network, as well as the enhancement in stability of emulsions and foams. ${ }^{20-27}$ The switching between cohesive interfacial network and detergent state can be achieved by adding chelating agents or by adjusting the $\mathrm{pH}$ to disrupt the histidine-metal ion interaction. ${ }^{20,25}$ 
To further explore the links between peptide sequence design, structure and function, two new peptides, AM-S and $\mathrm{C}_{8}$-AM, were designed by adding an additional hydrophobic module, aiming to achieve stronger anchoring at the interface to further enhance surface activity. Firstly, the surface activity of designed peptides was studied by measuring the dynamic interfacial tension of Miglyol oil in peptide solutions. Then, nanoemulsions were prepared using the designed peptide surfactants, and the effect of peptide concentration on droplet size was investigated. The stabilities of prepared nanoemulsions were monitored for 20 days. The stimuli-responsive properties of these nanoemulsions were also explored.

\section{EXPERIMENTAL SECTION}

Materials. Peptides AM-S (M 3261.64) and $\mathrm{C}_{8}$-AM ( $M$ 2571.04) were custom synthesized by GenScript Corporation (Piscataway, NJ). The purity of AM-S and $\mathrm{C}_{8}-\mathrm{AM}$ are $96.3 \%$ and 95.2\%, respectively, measured by reversed-phase high-performance liquid chromatography (RP-HPLC). The RP-HPLC and liquid chromatography-mass spectrometry (LC-MS) characterization for peptides AM-S and $\mathrm{C}_{8}-\mathrm{AM}$ were included in the Supporting Information (Figures S1-S4). The peptide content of lyophilized samples was determined by quantitative amino-acid analysis (Australian Proteome Analysis Facility, Sydney, Australia). Milli-Q water having a resistivity of $>18.2 \mathrm{M} \Omega \cdot \mathrm{cm}$ was obtained from a Milli-Q system equipped with a 0.22 $\mu \mathrm{m}$ filter (Merck Millipore, Merck KGaA, Darmstadt, Germany). Miglyol 812 oil was purchased from Caesar \& Loretz GmbH (Hilden, Germany) and passed through heat-activated silica gel (Sigma-Aldrich, Castle Hill, Australia) prior to use. Sodium 4-(2-hydroxyethyl)-1piperazine ethane sulfonate (HEPES) was from Sigma-Aldrich (Castle Hill, Australia) and was selected for its capacity to buffer at $\mathrm{pH} 7$ as well as its low-binding affinity for metal ions. All other chemicals were of analytical grade, obtained from Sigma-Aldrich and used as received unless otherwise stated. 
Circular Dichroism (CD). To determine secondary structures of the peptides in bulk solution, CD spectra of $100 \mu \mathrm{M}$ peptide in HEPES (1 mM, pH 7) were recorded on a Jasco J815 spectropolarimeter (Jasco Inc., Easton, MD) at $25^{\circ} \mathrm{C}$ in a $1 \mathrm{~cm}$-path-length quartz cell (Starna, Castle Hill, Australia). Far-UV CD spectra were monitored from 260 to $190 \mathrm{~nm}$ using $0.1 \mathrm{~nm}$ data pitch, $50 \mathrm{~nm} / \mathrm{s}$ scan speed, $2 \mathrm{~s}$ response time, $1 \mathrm{~nm}$ bandwidth, and 10 accumulations. The obtained raw ellipticity was converted to molar ellipticity using the following equation: ${ }^{28}$

$$
[\theta]=\frac{\theta \times M_{\mathrm{mrw}}}{10 \times C \times l}
$$

where $[\theta]$ is molar ellipticity (deg $\mathrm{cm}^{2} / \mathrm{dmol}$ ), $\theta$ is raw ellipticity (mdeg), $c$ is peptide concentration (M), $l$ is cell path length (cm), and $M_{\text {mrw }}$ is mean residue molecular mass i.e., peptide molecular mass/number of residues.

Interfacial Tension. Oil--water interfacial tension was studied using a Krüss drop shape analysis system DSA-10 (Krüss GmbH, Hamburg, Germany). Peptide solutions (8 mL) in HEPES (25 mM, pH 7) in the presence or absence of $\mathrm{ZnCl}_{2}$ were filled into an 8-mL quartz cuvette (Hellma GmbH, Müllheim, Germany). A Miglyol 812 oil droplet was formed manually in the peptide solution from a U-shaped stainless steel needle having a diameter of $1.507 \mathrm{~mm}$. The droplet shape was monitored automatically over $400 \mathrm{~s}$ to follow changes in the interfacial tension. Prior to the measurement, the interfacial tension of Miglyol 812 oil in the buffer in the absence of peptide was measured at approximately $32 \mathrm{mN} / \mathrm{m}$ which remained constant for at least 10 min to ensure correct functioning, focusing, and cleanliness of the instrument.

Interfacial Rheology. To study the interfacial rheology, sudden droplet contractions of Miglyol 812 oil in peptide solution ( $8 \mathrm{~mL}, 20 \mu \mathrm{M}$, pH 7) were carried out using a Krüss drop shape analysis system DSA-10. An oil droplet was formed in the peptide solution as previously 
described and aged for 40 mins. Subsequently, a sudden reduction in droplet volume was performed by withdrawing the oil droplet back into syringe. This process was recorded using a camera attached to the instrument.

Nanoemulsion Preparation and Characterization. Lyophilized peptide (AM-S or $\mathrm{C}_{8}$ AM) was dissolved in HEPES (25 mM, pH 7) to prepare peptide solutions at concentrations of 50, 100, 200, 400 and $800 \mu \mathrm{M}$, in which $\mathrm{ZnCl}_{2}$ was added at twice the molar concentration of the peptide. Miglyol 812 oil (2 v/v\%) was subsequently added into the peptide solution (1 mL) and homogenized using a Branson Sonifier 450 ultrasonicator (Branson Ultrasonics, Danbury, $\mathrm{CT}$ ) for either two (AM-S) or three $\left(\mathrm{C}_{8}-\mathrm{AM}\right) 30 \mathrm{~s}$ bursts at an energy output of $40 \mathrm{~W}$ and interspersed in an ice bath for $60 \mathrm{~s}$. To study the effect of storage temperature on the stability of nanoemulsions, each freshly-prepared nanoemulsion sample was divided into two volumetrically-equal aliquots and then stored at either $4{ }^{\circ} \mathrm{C}$ or $25^{\circ} \mathrm{C}$. The samples were taken intermittently over a 21-day period for characterization. To modulate the stability of nanoemulsions, an aliquot of $100 \mathrm{mM}$ ethylenediaminetetraacetic acid (EDTA) pH 7, sufficient to give a 5- to 10-fold molar excess over added zinc ions, was added into an aliquot of freshlyprepared nanoemulsion. The nanoemulsion samples, both in the presence and absence of EDTA, were incubated at $25^{\circ} \mathrm{C}$ and their physical appearances were monitored over 6-h period.

Dynamic Light Scattering (DLS). Z-average diameter, size distribution, and zeta potential of the nanoemulsion samples were measured by dynamic light scattering (DLS) using a Malvern Zetasizer Nano ZS (Malvern Instrument, UK) at a backscattering angle of $173^{\circ}$ and a temperature of $25{ }^{\circ} \mathrm{C}$. Each nanoemulsion sample was diluted by a factor of 50 in HEPES (25 mM, pH 7) prior to measurement to avoid multiple scattering effects. Data was analyzed by the DTS software (Malvern, version 7.11) using a non-negatively constrained least squares 
(NNLS) fitting algorithm. The refractive index, dielectric constant, and viscosity of the dispersant were assumed to be $1.33,78.5$, and $0.8872 \mathrm{cP}$ at $25^{\circ} \mathrm{C}$, respectively.

\section{RESULTS AND DISCUSSION}

Peptide Design. Two peptides, namely AM-S and $\mathrm{C}_{8}$-AM, were designed by modulating the AM1 sequence (Ac-MKQLADS LHQLARQ VSRLEHA-CONH$)_{2}^{20}$ with an additional hydrophobic moiety (Figure 1). Peptide AM-S (Ac-MKQLADS LHQLARQ VSRLEHA PSGAGAGAGY-CONH 2 ), having a theoretical molecular mass $3.26 \mathrm{kDa}$ and $\mathrm{pI}$ 8.38, was designed with the additional octapeptide (GAGAGAGY) at the $C$-terminal of AM1 peptide via a Proline-Serine linker. The proline, having the lowest helix propensity, serves to break the preceding helix, ${ }^{29}$ while serine provides rotational freedom. ${ }^{30,31}$ The additional octapeptide, derived from Bombyx mori silkworm fibroin, ${ }^{32}$ was observed to self-assemble to a $\beta$-sheet conformation in bulk solution, with slight shift in morphology from planar $\beta$-sheet at $\mathrm{pH} 4$ to twisted $\beta$-sheet at $\mathrm{pH} 9 .{ }^{31}$ It is expected that the additional octapeptide with the repeating hydrophobic amino acid, alanine, could act as an anchoring chain and inhibit the detachment of AM-S from the interface. Similarly, the peptide $\mathrm{C}_{8}-\mathrm{AM}\left(\mathrm{C}_{8} \mathrm{H}_{16}-\mathrm{MKQLADS}\right.$ LHQLARQ VSRLEHA-CONH 2 ), having a theoretical molecular mass $2.57 \mathrm{kDa}$ and $\mathrm{pI}$ 8.54, was designed with the modification of nonanoic acid at the $N$-terminal. The hydrophobic alkyl tail was expected to be an even stronger anchor to the oil phase to promote stable adsorption of $\mathrm{C}_{8}$-AM at oil-water interface. ${ }^{33-34} \mathrm{C}_{8}$-AM was only amidated at the C-terminal since the $\mathrm{N}$-terminal was blocked by the uncharged alkyl tail. In comparison with AM1, AM-S and C8-AM were purposely designed to achieve strong adsorption at the oil-water interface, thus enhancing the capability of forming nanoemulsions as well as their stability. 


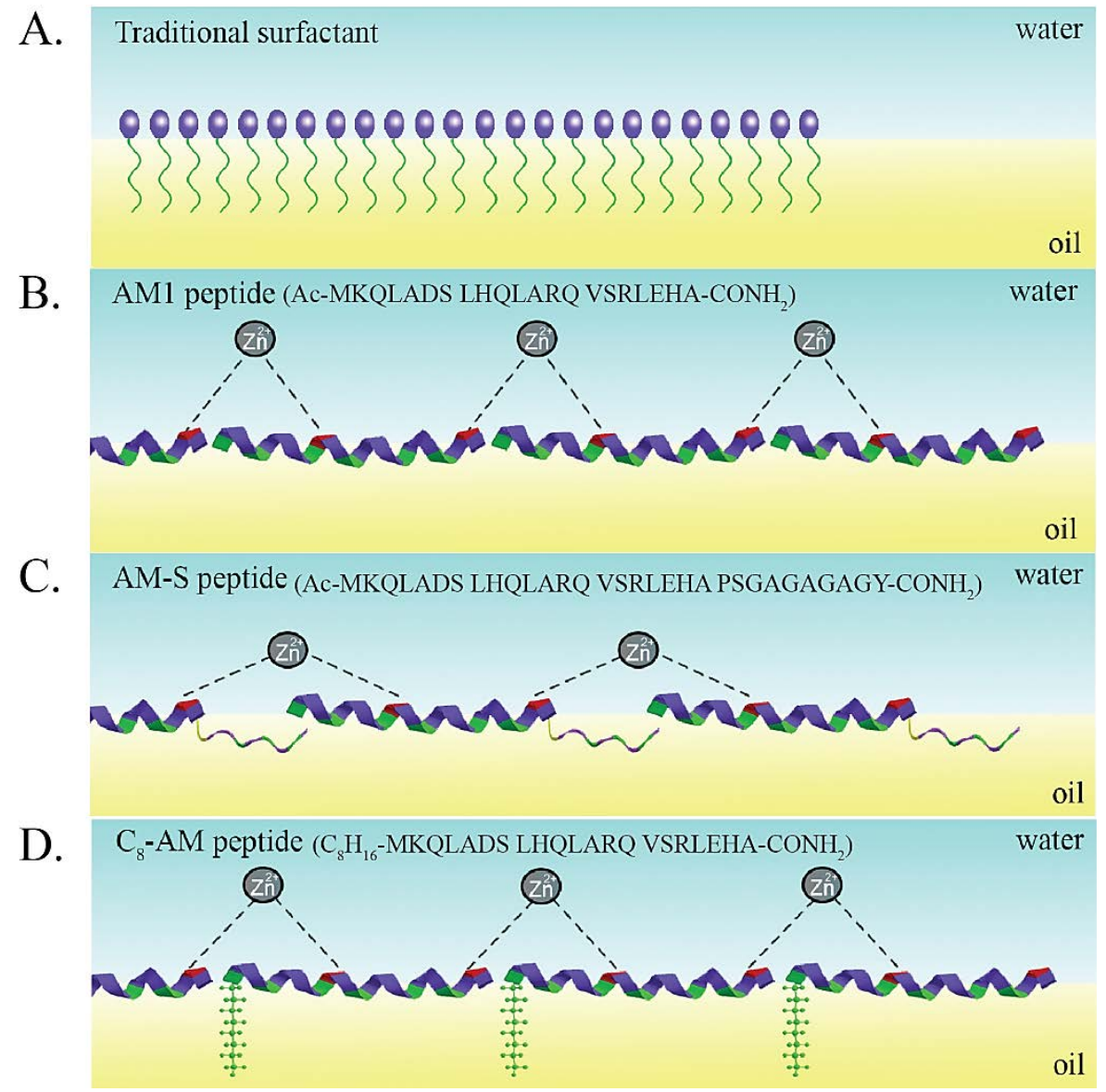

Figure 1. Illustrations of different surfactants adsorbed at oil-water interfaces. (A) Traditional surfactants with hydrophilic heads and hydrophobic tails; (B) Designer peptide AM1; Possible structure of designer peptides (C) AM-S and (D) $\mathrm{C}_{8}$-AM.

Peptide Conformations in Bulk Solutions. The conformations of peptides AM-S and $\mathrm{C}_{8-}$ AM in bulk solutions were investigated at neutral $\mathrm{pH}$ using Circular dichroism (CD) (Figure 2). The CD spectrum of AM-S showed a strong negative band near $200 \mathrm{~nm}$ and a weak negative shoulder at $217 \mathrm{~nm}$, indicating a disordered secondary structure ${ }^{35}$ in solution. This is consistent with that of the AM1 peptide which was found to exist predominantly as unstructured monomers in bulk solution, ${ }^{25-26}$ indicating that the additional octapeptide does not affect the structure of AM1. Moreover, the addition of $\mathrm{Zn}^{2+}$ to the AM-S solution had no significant effect on the secondary structure of AM-S in peptide solution, which reveals that the self-assembly of $\alpha$-helical structure does not happen in the bulk solution. Noticeably, the CD spectra of $\mathrm{C}_{8^{-}}$ 
AM in solution appeared a typical spectra of $\alpha$-helical conformation, with a prominent double minimum at 209 and $222 \mathrm{~nm}$ and a positive band at $193 \mathrm{~nm},{ }^{35}$ suggesting $\mathrm{C}_{8}$-AM's $\alpha$-helical conformation in bulk solution. Forns et al had reported a similar phenomenon that conjugating peptides to monoalkyl hydrocarbon chains had a tendency to stabilize helix formation of short peptides. ${ }^{36}$ They observed that a 16-residue peptide alone did not form a distinct structure in solution, while the addition of $\mathrm{C}_{6}$ or $\mathrm{C}_{16}$ monoalkyl hydrocarbon chain at the $\mathrm{N}$ terminal turned the peptide into $\alpha$-helical structure in solution. Moreover, the additional $\mathrm{Zn}^{2+}$ led to a more negative value at 209 and $222 \mathrm{~nm}$, suggesting slightly enhanced $\alpha$-helicity, which is probably due to the histidine- $\mathrm{Zn}^{2+}$ interaction that promotes a better ordered arrangement of peptides. It is worth noting that $\alpha$-helical peptides like AM1 (the parent peptide for AM-S and $\mathrm{C}_{8}$-AM) have high solubility in aqueous solutions. ${ }^{21,37-38}$ They do form soluble clusters of typically 2 (dimer) to 4 (tetramer) peptides over a broad range of concentrations, ${ }^{21}$ but they don't aggregate or form micelles in solutions. Therefore, peptide surfactants don't have a critical micelle concentration (CMC) or critical aggregation concentration (CAC). ${ }^{39-40}$ 

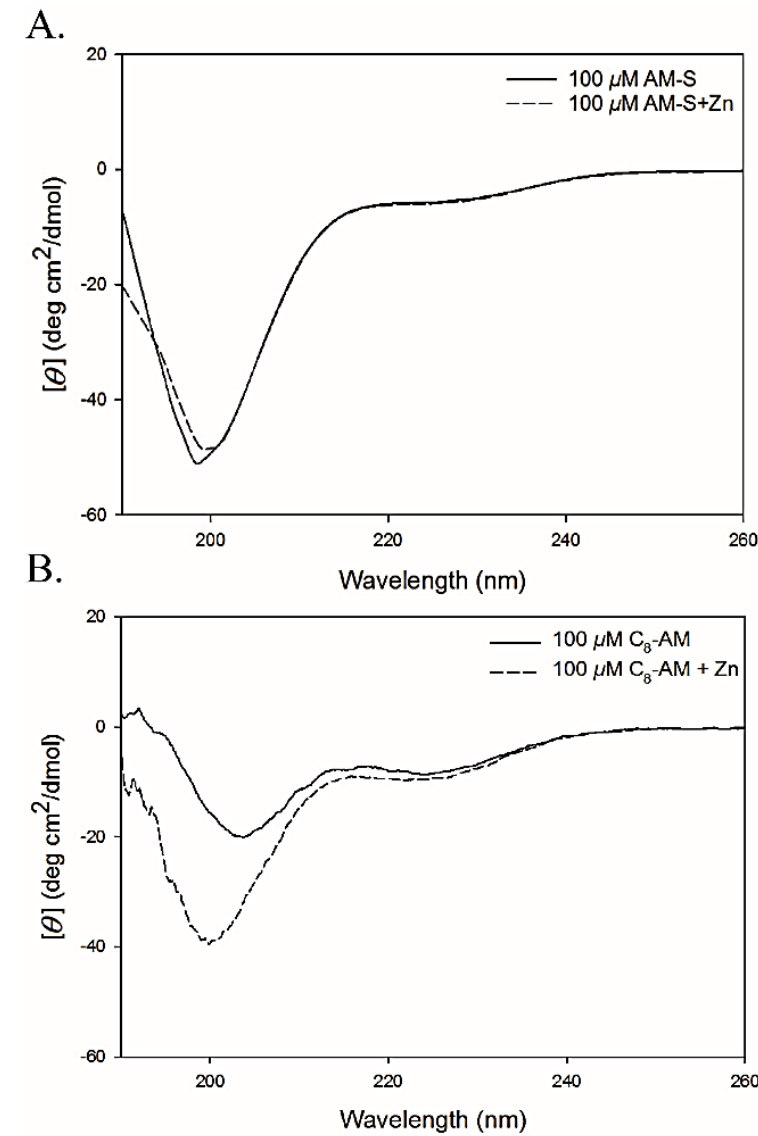

Figure 2. Circular dichroism spectra of peptides (A) AM-S and (B) $C_{8}-A M$. Spectra were recorded for $100 \mu \mathrm{M}$ peptide in $1 \mathrm{mM}$ HEPES pH 7 in the presence and absence of $200 \mu \mathrm{M}$ $\mathrm{ZnCl}_{2}$.

Peptide Surface Activity. The dynamic interfacial tensions of AM-S and $\mathrm{C}_{8}$-AM (Miglyol 812 oil in peptide solutions) were measured using the Drop Shape Analysis at three different peptides concentrations, i.e., 1, 5, 10, 20 and $80 \mu \mathrm{M}$ in HEPES buffer (25 mM, pH 7) in the presence and absence of $\mathrm{ZnCl}_{2}$ (Figure 3). The result demonstrated excellent surface activity for both AM-S and $\mathrm{C}_{8}$-AM as indicated by the rapid decrease of the interfacial tension. It's suspected that similar to AM1, AM-S folds into $\alpha$-helical structure during interfacial selfassembly, while the self-assembly of $\mathrm{C}_{8}$-AM occurs in the bulk solution as assessed by circular dichroism. Both peptides would quickly adsorb at oil-water interface and form a thin interfacial film with ordered peptides to stabilize the interface and reduce interfacial tension. In the 
presence of $\mathrm{Zn}^{2+}$ in the solution, the histidine residues orienting towards the water phase would interact with $\mathrm{Zn}^{2+}$ and form metal ion bridges between adjacent adsorbed peptides. Such intermolecular crosslinking of peptides lead to stronger interfacial films, hence more stabilized oil-water interface.

The oil-water interfacial tension kinetics for AM-S peptides at concentrations ranging from 1 to $80 \mu \mathrm{M}$ in the absence and presence of $\mathrm{Zn}^{2+}$ are shown in Figures $3 \mathrm{~A}$ and $3 \mathrm{~B}$, respectively. In the absence of $\mathrm{Zn}^{2+}, 1 \mu \mathrm{M}$ AM-S exhibited a slow decrease in interfacial tension and it took approximately $900 \mathrm{~s}$ to reach an equilibrium interfacial tension of $18.4 \pm 0.4 \mathrm{mN} / \mathrm{m}$. At AM-S concentrations of 5, 10 and $20 \mu \mathrm{M}$, a rapid decrease was complete in less than $60 \mathrm{~s}$ and the plateau interfacial tension values reached were similar, that is, $17.1 \pm 0.4,17.2 \pm 0.6$ and 17.0 $\pm 0.2 \mathrm{mN} / \mathrm{m}$, respectively. Increasing the AM-S concentration to $80 \mu \mathrm{M}$ decreased the equilibrium interfacial tension further to $14.8 \pm 0.4 \mathrm{mN} / \mathrm{m}$. The AM-S concentration of $1 \mu \mathrm{M}$ in the presence of $\mathrm{Zn}^{2+}$ has a similar trend as that in the absence of $\mathrm{Zn}^{2+}$, and a slow decrease in interfacial tension was also observed before reaching the interfacial tension to a final value of $18.7 \pm 0.4 \mathrm{mN} / \mathrm{m}$ after $800 \mathrm{~s}$. The interfacial tension kinetics of AM-S concentrations of 5 , 10, 20 and $80 \mu \mathrm{M}$ in the presence of $\mathrm{Zn}^{2+}$ resemble closely those of AM-S without $\mathrm{Zn}^{2+}$, with most of the decrease in interfacial tension occurring in the first $60 \mathrm{~s}$, and reaching statistically identical final values of $18.1 \pm 0.6,16.4 \pm 0.5,16.4 \pm 0.2$ and $14.6 \pm 0.3 \mathrm{mN} / \mathrm{m}$, respectively. The slower interfacial adsorption of AM-S at low concentrations was mainly due to the slow diffusion of the peptide molecules. It is known that interfacial adsorption of peptide surfactant was controlled by diffusion of the peptide to the subinterfacial region prior to interfacial adsorption in which the diffusion time is inversely proportional to the square of bulk peptide concentration $\left(t_{d} \propto C_{\infty}{ }^{-2}\right) .{ }^{41}$ 
Figures $3 \mathrm{C}$ and $3 \mathrm{D}$ show the interfacial tension kinetics of $\mathrm{C}_{8}$ - $\mathrm{AM}$ at five different concentrations $(1,5,10,20$ and $80 \mu \mathrm{M})$ in the absence and presence of $\mathrm{Zn}^{2+}$, respectively. It can be clearly seen that $\mathrm{C}_{8}$-AM adsorption is much slower than that of AM-S with ultralow interfacial tensions. In addition, the effect of $\mathrm{Zn}^{2+}$ on interfacial tension of $\mathrm{C}_{8}-\mathrm{AM}$ is also not significant, similar to AM-S. Peptide $\mathrm{C}_{8}-\mathrm{AM}$ at $1 \mu \mathrm{M}$ in the absence and presence of $\mathrm{Zn}^{2+}$ showed a gradual decrease in interfacial tensions within $1000 \mathrm{~s}$ before reaching final values of $9.8 \pm 0.9$ and $10.8 \pm 0.8 \mathrm{mN} / \mathrm{m}$, respectively. As the peptide concentration increases, the interfacial tension decreases more rapidly. The final interfacial tensions of $80 \mu \mathrm{M} \mathrm{C}_{8}-\mathrm{AM}$ in the absence and presence of $\mathrm{Zn}^{2+}$ were reached in less than $60 \mathrm{~s}$, that is, $7.0 \pm 0.2$ and $7.2 \pm 0.1$ $\mathrm{mN} / \mathrm{m}$, respectively. Unlike the AM-S peptide, the slow kinetics of $\mathrm{C}_{8}-\mathrm{AM}$ might be due to the secondary $\alpha$-helical structure of $\mathrm{C}_{8}$-AM in the bulk solution as well as the hydrophobic interactions between the $\mathrm{C}_{8}$ tails (Figure $2 \mathrm{~B}$ ), so it takes longer time for $\mathrm{C}_{8}$-AM to adjust and adsorb at the interface in comparison with the random structured AM-S peptide (Figure 2A). 
A.

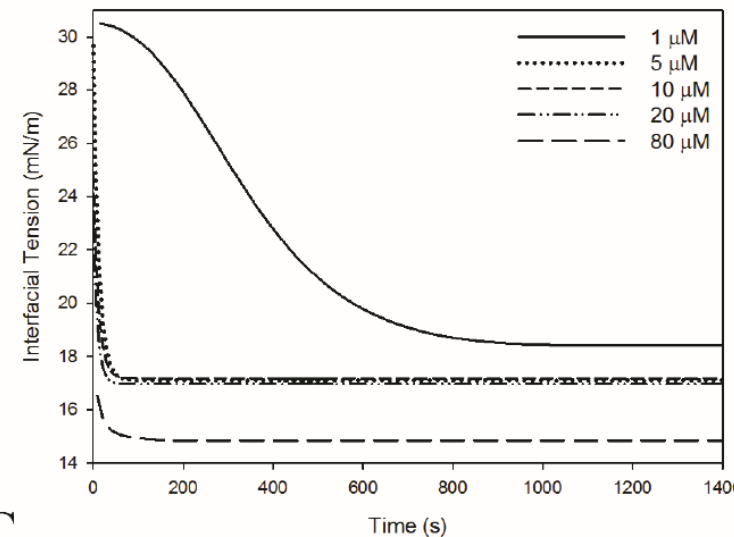

C.

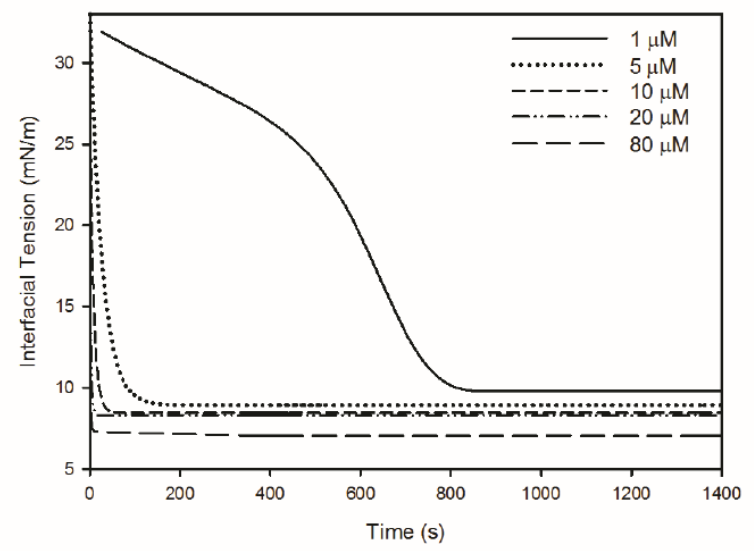

B.

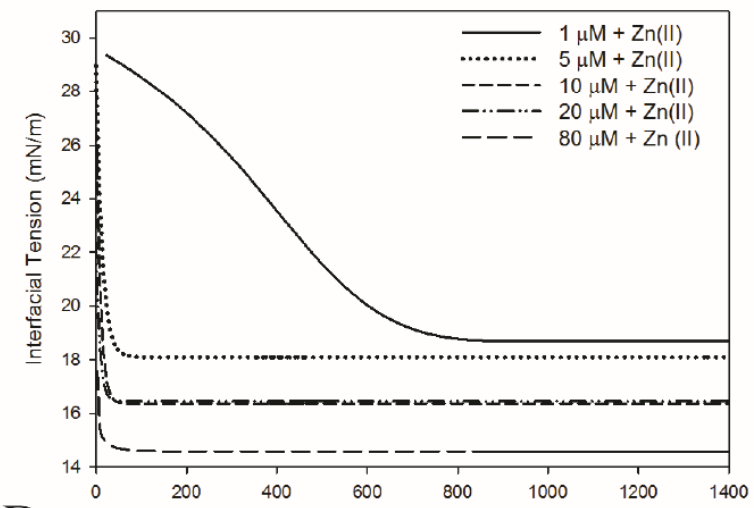

D.

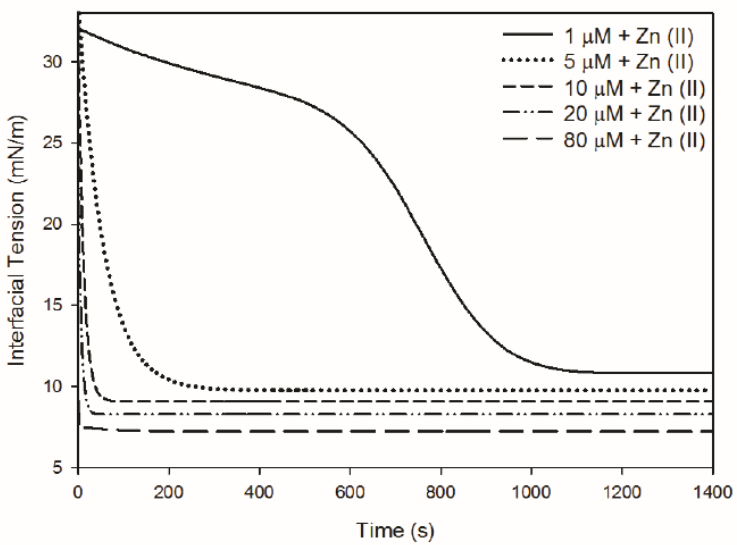

Figure 3. Dynamic oil-water interfacial tension of peptides: (A) AM-S; (B) AM-S $+\mathrm{Zn}^{2+}$; (C) $\mathrm{C}_{8}$-AM; and (D) $\mathrm{C}_{8}-\mathrm{AM}+\mathrm{Zn}^{2+}$. Peptides were in $25 \mathrm{mM}$ HEPES $\mathrm{pH} 7$ in the absence or presence of $\mathrm{ZnCl}_{2}$, in which $\mathrm{ZnCl}_{2}$ was added at twice the molar concentration of the peptides.

In order to examine whether a peptide-metal ion interfacial network was formed at the oilwater interface, contraction experiments were conducted to visually observe the shrinkage of oil droplets (Figure 4). For both AM-S and $\mathrm{C}_{8}$-AM solution, when the volume of oil droplets decreased rapidly and significantly, a wrinkled surface could be observed indicating the formation of an interfacial network. This is not surprising, as the DSA results suggested that both peptides are able to adsorb at interface to reduce the interfacial tension, and the interaction between peptides and metal ion can be indicated by the distinctive adsorption kinetics under different metal ion conditions. The presence of interfacial wrinkles confirmed the formation of the interfacial peptide networks mediated by metal ions (Zn). 
A.

B.
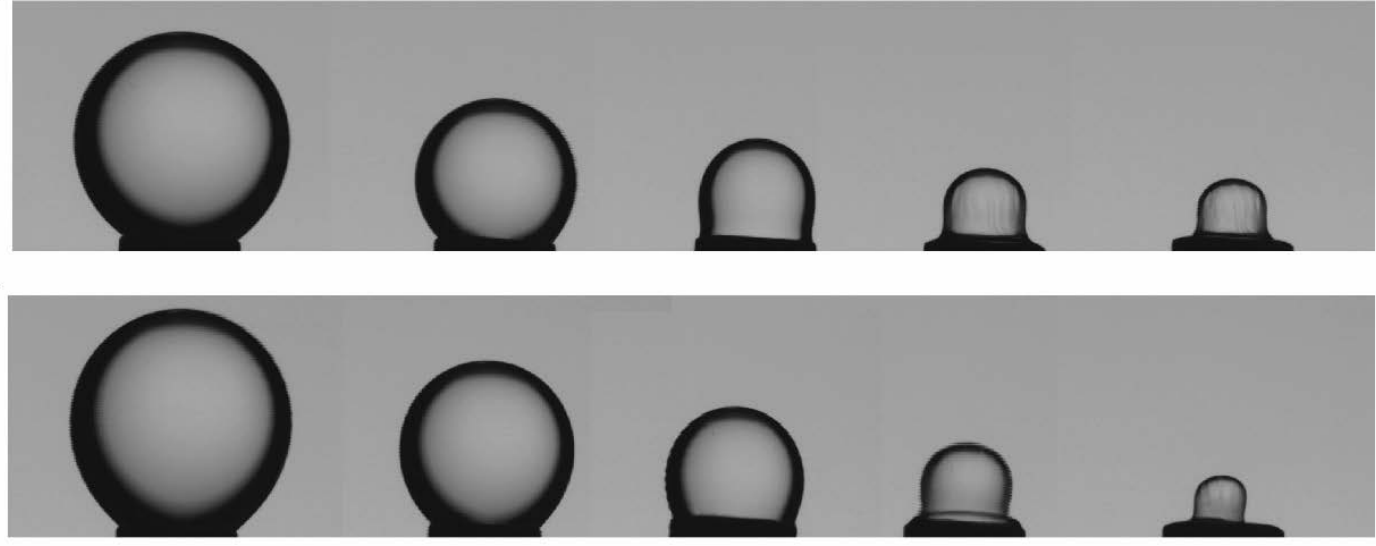

Figure 4. Photographs of a 40-min-old Miglyol 812 oil droplet from an inverted needle in 20 $\mu \mathrm{M}$ peptide (A) AM-S and (B) $\mathrm{C}_{8}$-AM in the presence of $40 \mu \mathrm{M} \mathrm{ZnCl}_{2}$ and then subjected to a sudden contraction in the droplet volume.

Nanoemulsion Formation and Stability. We further investigated the emulsification capability of AM-S and $C_{8}$-AM. Nanoemulsions of 2 v/v\% Miglyol 812 oil were prepared in either AM-S or $\mathrm{C}_{8}$-AM peptide solution at different concentrations (i.e., 50, 100, 200, 400, 800 $\mu \mathrm{M}$ ) in HEPES buffer (25 mM, pH 7) using short sonication burst cycles of 30 seconds duration. Firstly, we investigated the effect of energy input on nanoemulsion size. With the intensity of sonication kept consistent, longer sonication time provides more energy input to disrupt oil into droplets. $^{42-43}$ Figure 5 shows that nanoemulsion size of both AM-S and $\mathrm{C}_{8}$-AM at low concentrations increased with more sonication cycles, indicating that excess energy input destabilized the emulsions. $50 \mu \mathrm{M}$ AM-S produced nanoemulsions with sizes of 272.8, 329.6 and $423.5 \mathrm{~nm}$, respectively, using 2, 3 and 4 sonication burst cycles, and their polydispersity (Đ) increased correspondingly from 0.191 to 0.385 . Similarly, $50 \mu \mathrm{M} \mathrm{C}_{8}$-AM generated nanoemulsions with size from $378.9 \mathrm{~nm}(\bigoplus=0.21)$ to $532.9 \mathrm{~nm}(\bigoplus=0.25)$ with prolonged sonication time. At low concentrations, peptides were insufficient to fully cover the oil-water interface, especially the surface of newly formed droplets to effectively prevent coalescence. While longer sonication time was applied, the collision rate of oil droplets increases which 
favors coalescence, leading to larger size of prepared nanoemulsions. ${ }^{43-44}$ However, as peptide concentration increased (200 $\mu \mathrm{M}$ for AM-S and $100 \mu \mathrm{M}$ for $\mathrm{C}_{8}$-AM), the impact of sonication time on the size of nanoemulsions became less significant. The size of nanoemulsions prepared using $400 \mu \mathrm{M}$ AM-S and $400 \mu \mathrm{M} \mathrm{C}_{8}$-AM with different sonication cycles reached $192 \pm 1 \mathrm{~nm}$ $(Đ=0.20)$ and $172 \pm 3 \mathrm{~nm}(Đ=0.17)$, because at high concentrations, the coverage of peptides at oil-water interface increased, thus the size of nanoemulsions was predominantly affected by the surface activity of the peptide surfactant rather than energy input. ${ }^{45}$ Therefore, in the following experiments we used 2 sonication burst cycles and 3 sonication burst cycles to prepare AM-S and $\mathrm{C}_{8}-\mathrm{AM}$ nanoemulsions, respectively.
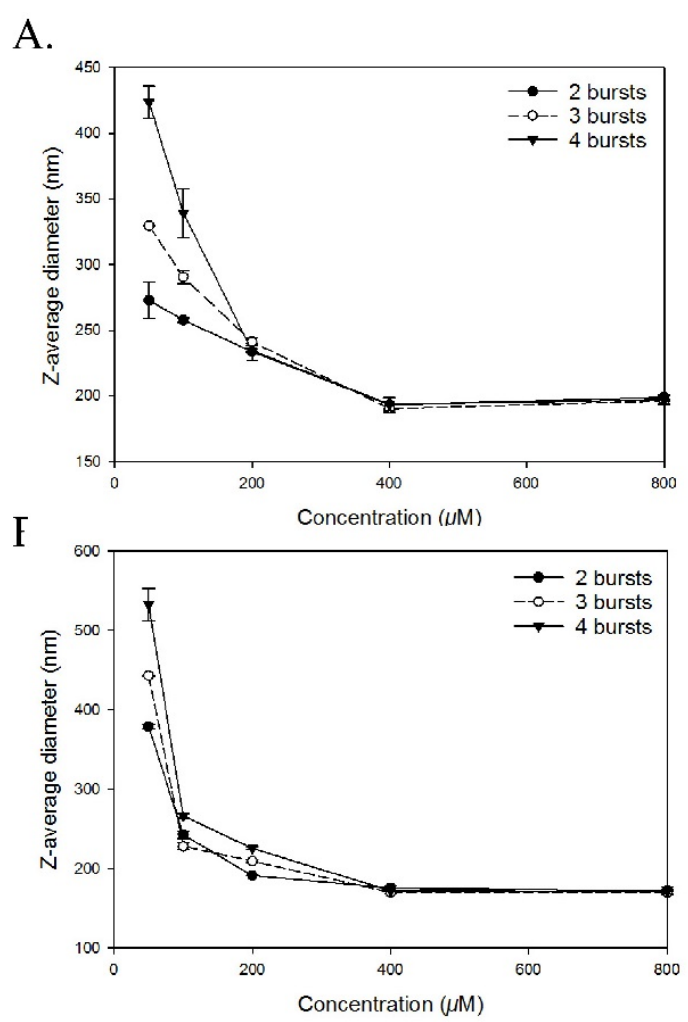

Figure 5. Dependent of Z-average diameter of nanoemulsions on sonication time. Peptides used were (A) AM-S and (B) $\mathrm{C}_{8}$-AM in HEPES (25 mM, pH 7) in which $\mathrm{ZnCl}_{2}$ was added at twice the molar concentration of the peptides. 
To study the capability of the peptide AM-S and $\mathrm{C}_{8}$-AM in making and stabilizing emulsions, oil-in-water emulsions containing 2 v/v\% Miglyol 812 oil were prepared using peptides at different concentrations (i.e., 50, 100, 200, 400, $800 \mu \mathrm{M}$ ) in HEPES buffer (25 mM, $\mathrm{pH}$ 7). Figure 6 shows the Z-average droplet diameter and zeta potential of freshly prepared nanoemulsions as a function of peptide concentration. Low peptide concentrations of both AMS and $\mathrm{C}_{8}$-AM (50 $\mu \mathrm{M}$ and $\left.100 \mu \mathrm{M}\right)$ generated emulsions with bigger droplet size and smaller zeta potential, indicating that peptides in solution were insufficient to cover the droplet surface. ${ }^{23}$ As the peptide concentration increased to $200 \mu \mathrm{M}$ or even higher (400 and $800 \mu \mathrm{M}$ ), the size of emulsions dropped to below $200 \mathrm{~nm}$, and the zeta potential increased to around +50 $\mathrm{mV}$. In comparison with the $400 \mu \mathrm{M}$ AM-S nanoemulsions having a size of $190 \pm 1 \mathrm{~nm}$ ( $Đ=0.223$ ) and a zeta potential of $50 \pm 1 \mathrm{mV}, 400 \mu \mathrm{M} \mathrm{C}_{8}$-AM yielded nanoemulsions with a

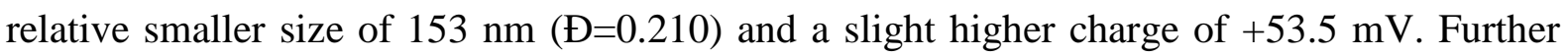
increasing the peptide concentration had no significant effect on reducing the droplet size. The results suggested that the peptide surfactants with a concentration of $400 \mu \mathrm{M}$ are sufficient to produce nanoemulsions with small droplet size and good monodispersity. It is worth noting that both AM-S and $\mathrm{C}_{8}$-AM-based nanoemulsions have high positive charge (above $+35 \mathrm{mV}$ ) even at low peptide concentration, which further increases to around $+50 \mathrm{mV}$ with the increase of peptide concentrations. The high positive charge of nanoemulsions is probably resulted from the positive charge of both $\mathrm{AM}-\mathrm{S}$ and $\mathrm{C}_{8}-\mathrm{AM}$ at neutral $\mathrm{pH}$, together with the association of $\mathrm{Zn}^{2+}$ in the intermolecular networks at the interface. ${ }^{23-24,46} \mathrm{As}$ a rule of thumb, nanoemulsions with absolute zeta potentials above $30 \mathrm{mV}$ are electrically stabilized. ${ }^{47}$ Therefore, nanoemulsions prepared using high concentration of surfactant peptides are considered to have strong electrical repulsion among droplets to enhance stability against coalescence. Additionally, the overall zeta potentials of $\mathrm{C}_{8}$-AM-based nanoemulsions are slightly higher 
than that of the AM-S-based nanoemulsions, which is probably due to the higher $\mathrm{pI}$ of $\mathrm{C}_{8}$ - $\mathrm{AM}$ that causes peptide molecules to carry more surface charges at neutral $\mathrm{pH}$.

A.

B.
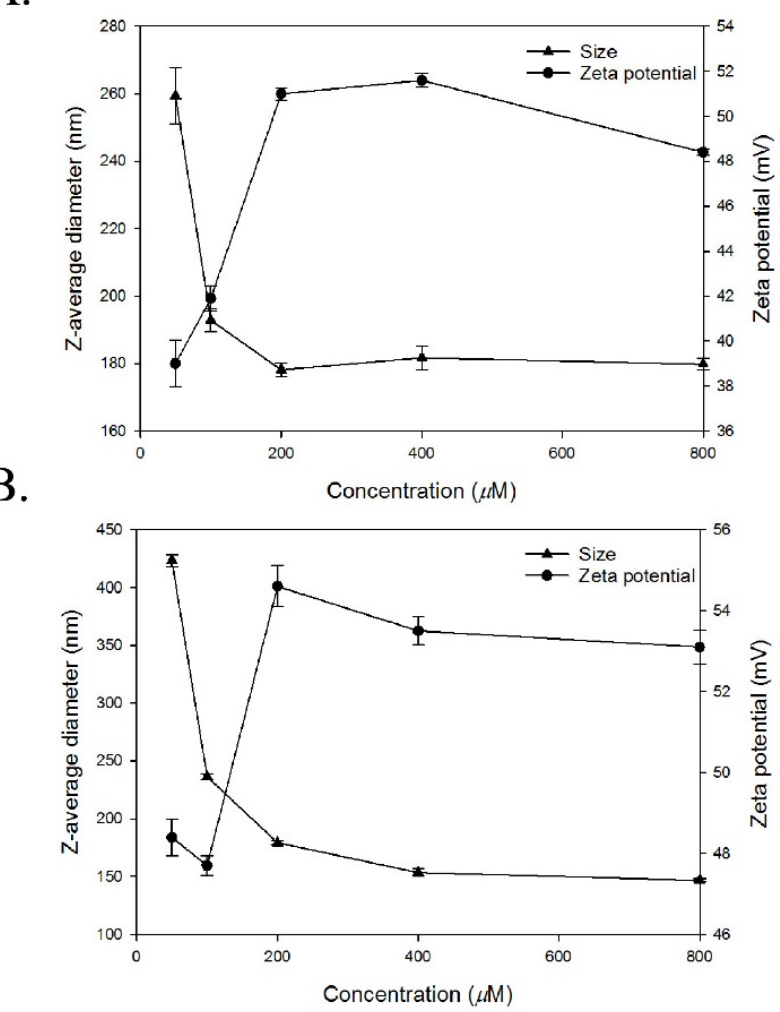

Figure 6. Dependence of Z-average diameter and zeta potential of nanoemulsions on peptide concentration. Peptides used were (A) AM-S and (B) $\mathrm{C}_{8}$-AM in HEPES (25 mM, pH 7) in which $\mathrm{ZnCl}_{2}$ was added at twice the molar concentration of the peptides.

We further investigated nanoemulsions' stability over three weeks at $4{ }^{\circ} \mathrm{C}$ and $25{ }^{\circ} \mathrm{C}$. Nanoemulsions were prepared using AM-S and $\mathrm{C}_{8}$-AM peptides with concentrations ranging from $50 \mu \mathrm{M}$ to $800 \mu \mathrm{M}$ and stored at $4{ }^{\circ} \mathrm{C}$ and $25^{\circ} \mathrm{C}$, respectively. Figure 7 shows the variation of the size and zeta potential of the AM-S nanoemulsions formed from three different concentrations (200, 400 and $800 \mu \mathrm{M}$ ) over 21 days. Low concentrations (50-100 $\mu \mathrm{M})$ of AMS were unable to make nanoemulsions having long-term stability. The droplet sizes gradually

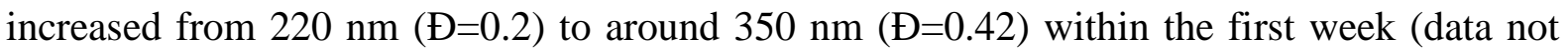
shown). In contrast, nanoemulsions prepared using 200, 400 and $800 \mu \mathrm{M}$ AM-S were stable at 
both temperatures over 21 days, and the size of nanoemulsions remained at around $180 \mathrm{~nm}(\bigoplus$ varied from 0.17 to 0.24 ). Over this period of storage time (21 days) at both $4{ }^{\circ} \mathrm{C}$ and $25{ }^{\circ} \mathrm{C}$, the droplet size and zeta potential showed little variation. The overall zeta potentials of nanoemulsions were around $50 \mathrm{mV}$, which was considered sufficient to diminish the intermolecular attraction and prevent further aggregation and coalescence of the system. ${ }^{48}$ Moreover, it is expected that the strong viscoelastic intermolecular film also contributed to promoting the stability of nanoemulsion, as a highly elastic interfacial layer could reduce film drainage and resist interfacial-layer rupture to better stabilize the interface against Ostwald ripening. ${ }^{22,49}$ The result showed that an AM-S concentration of $400 \mu \mathrm{M}$ is sufficient in stabilizing nanoemulsions for over three weeks with fine average size of droplets, narrow size distribution and high zeta potentials. 
A.

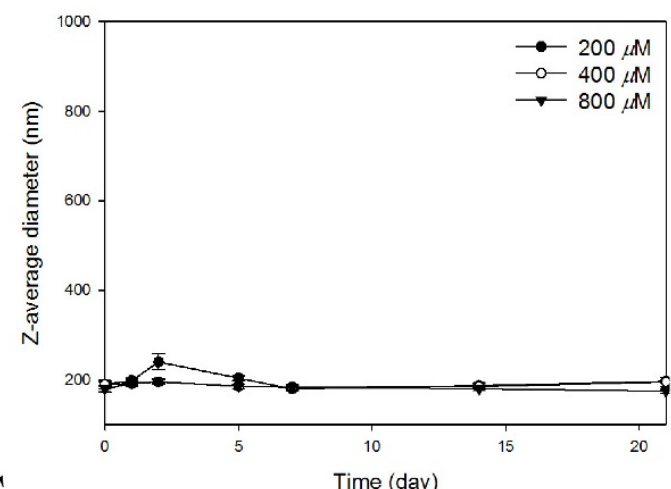

C.

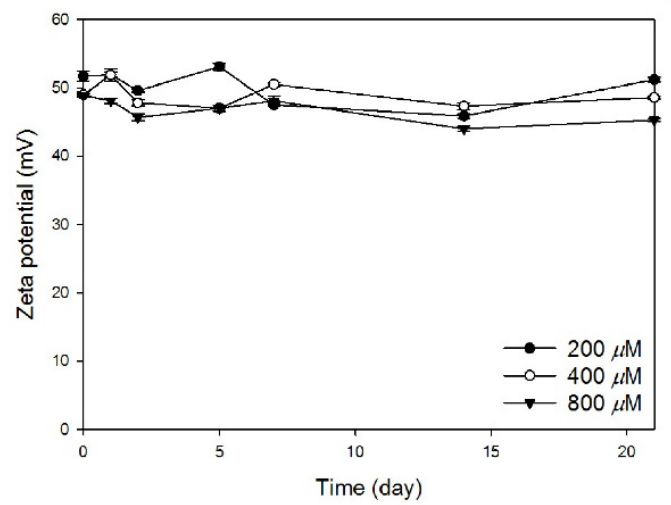

B.

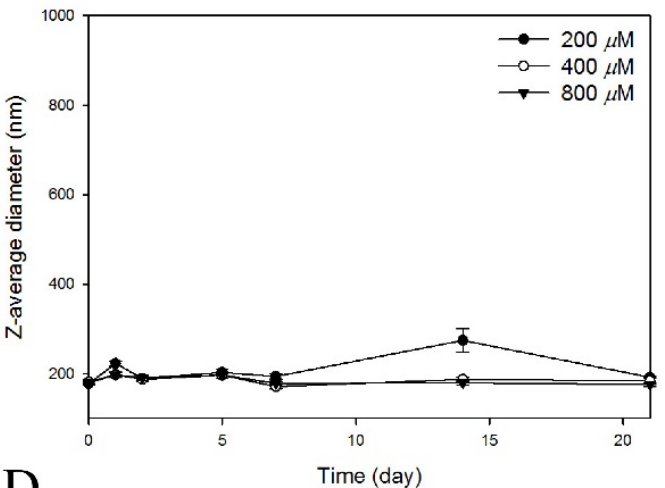

D.

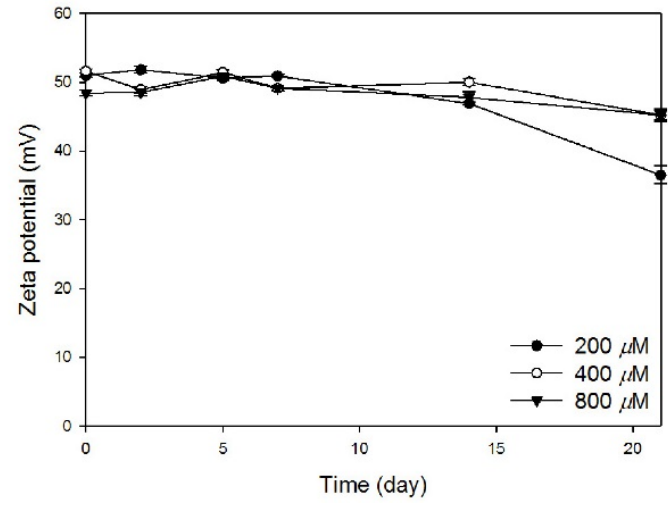

Figure 7. (A, B) Z-average diameter and (C, D) zeta potential of the AM-S nanoemulsions (2 $\mathrm{v} / \mathrm{v} \%$ Miglyol 812, $\mathrm{ZnCl}_{2}$ at twice the concentration of AM-S, $25 \mathrm{mM}$ HEPES, $\mathrm{pH}$ 7) stored at (A, C) $4{ }^{\circ} \mathrm{C}$ and (B, D) $25^{\circ} \mathrm{C}$ for 21 days.

Figure 8 shows the droplet size and zeta potential of $\mathrm{C}_{8}$-AM nanoemulsions using different concentrations of the $\mathrm{C}_{8}$-AM peptide surfactant at $4{ }^{\circ} \mathrm{C}$ and $25^{\circ} \mathrm{C}$ over 20 days. Similar to AMS nanoemulsions, the $50 \mu \mathrm{M} \mathrm{C}_{8}$-AM nanoemulsion was unstable with droplet size increasing dramatically from $423 \mathrm{~nm}$ to around $800 \mathrm{~nm}$ in the first five days, and the polydispersity (Đ) increased from 0.10 to around 0.40 (data not shown). However, it is noteworthy from Figure 8 that a lower $\mathrm{C}_{8}$-AM concentration of $100 \mu \mathrm{M}$ was able to effectively stabilize nanoemulsions with an average size of $236 \mathrm{~nm}(\mathrm{\Theta}=0.16)$ for 20 days at both storage temperature. Further increasing the $\mathrm{C}_{8}$ - $\mathrm{AM}$ concentration up to $800 \mu \mathrm{M}$ led to smaller droplets sizes. $800 \mu \mathrm{M} \mathrm{C}_{8}$ AM produced nanoemulsions of $147 \mathrm{~nm}(\bigoplus=0.20)$. The decrease in nanoemulsion size with increasing $\mathrm{C}_{8}-\mathrm{AM}$ concentrations was distinctively different from the AM-S nanoemulsions, 
which had a constant droplet size over the concentration range of 200-800 $\mu \mathrm{M}$. Regarding the surface charges, a slight decrease of zeta potential in $100 \mu \mathrm{M} \mathrm{C}_{8}$-AM nanoemulsions stored at $25{ }^{\circ} \mathrm{C}$ was observed for the first week, which is similar to that of the $200 \mu \mathrm{M}$ AM-S nanoemulsion. It is believed that at higher temperature the more-rapid Brownian motion led to increased collision rate between droplets. ${ }^{50}$ Thus nanoemulsions prepared using less peptides were insufficient to stabilize nanoemulsions against coalescence. By comparing the changes in size and zeta potential of nanoemulsions, the lower storage temperature of $4{ }^{\circ} \mathrm{C}$ is preferable for preserving the stability of nanoemulsions at lower peptide concentrations. When the concentration is high enough ( $200 \mu \mathrm{M}$ or above), the nanoemulsions prepared remain stable at both $4{ }^{\circ} \mathrm{C}$ and $25^{\circ} \mathrm{C} . .^{24,51}$

A.

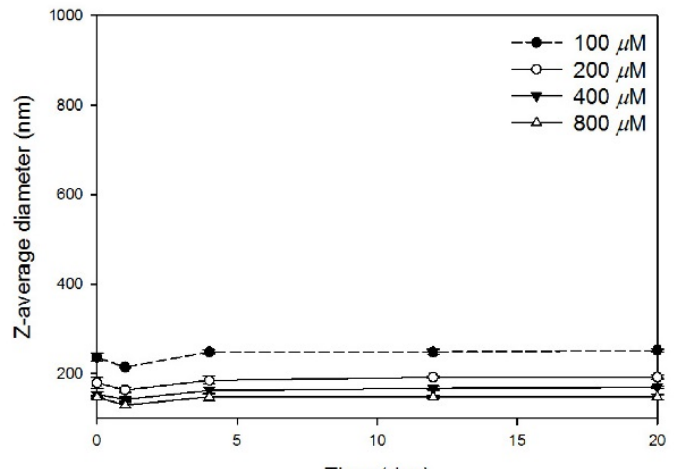

C.

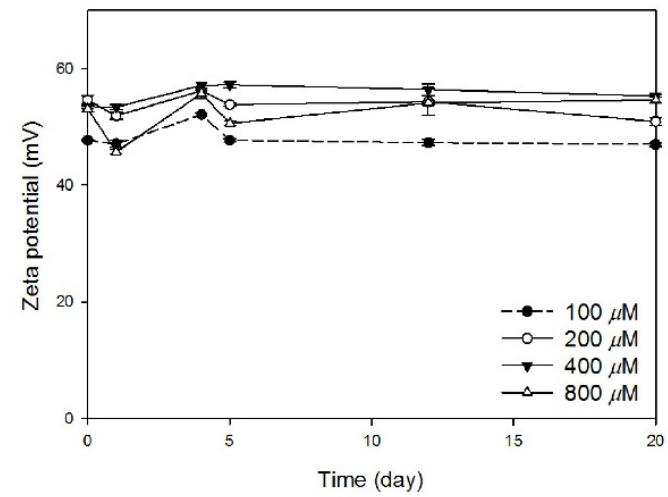

B.

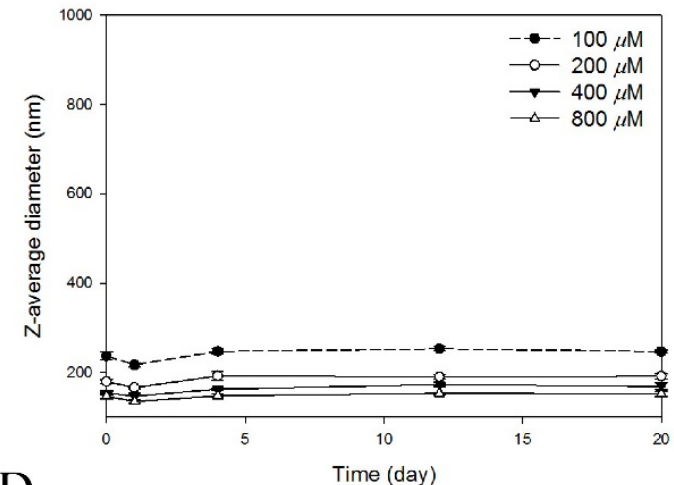

D.

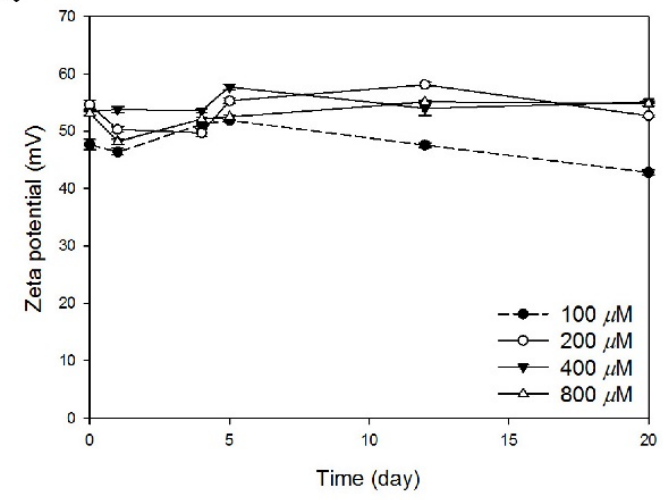

Figure 8. (A, B) Z-average diameter and (C, D) zeta potential of the $\mathrm{C}_{8}$-AM nanoemulsions (2 v/v\% Miglyol 812, $\mathrm{ZnCl}_{2}$ at twice the concentration of $\mathrm{C}_{8}-\mathrm{AM}, 25 \mathrm{mM}$ HEPES, $\mathrm{pH}$ 7) stored at $(\mathrm{A}, \mathrm{C}) 4^{\circ} \mathrm{C}$ and $(\mathrm{B}, \mathrm{D}) 25^{\circ} \mathrm{C}$ for 20 days. 
To further explore the histidine-metal ion interaction at the interface and thus the formation of interfacial network, we added a small amount of a chelating agent (EDTA, ethylenediaminetetraacetic acid) to the peptide stabilized nanoemulsions to disrupt metalhistidine binding. Figure 9 shows the stability of the nanoemulsions with and without EDTA over time. While the nanoemulsions prepared using either AM-S or $\mathrm{C}_{8}$-AM peptides remained stable for 6 hours, the additional EDTA led to gradual coalescence and phase separation, indicating that the metal-histidine binding was disrupted and the nanoemulsions were destabilized. Compared to AM-S nanoemulsion which responded to EDTA stimuli after 20 minutes, $\mathrm{C}_{8}$-AM nanoemulsion remained stable for up to 6 hours before coalescence was observed. It is probably because the long carbon chain at the N-terminal of $\mathrm{C}_{8}-\mathrm{AM}$ anchored deeply into the oil phase, allowing strong adsorption of $\mathrm{C}_{8}-\mathrm{AM}$ peptides at oil-water interface. $^{52}$ Hence the disruption of peptide-metal ion crosslink did not lead to immediate detachment of $\mathrm{C}_{8}$-AM at interface, and the $\mathrm{C}_{8}$-AM nanoemulsions were still stabilized by the adsorbed interfacial peptides, until coalescences between oil droplets eventually led to phase separation. This result showed that the stability of nanoemulsions prepared using AM-S or $\mathrm{C}_{8}$ AM can be actively reversed by adding chelating agent to disrupt the intermolecular crosslink between peptides, and AM-S nanoemulsions responded to the stimuli more effectively. 
$\mathrm{t}=0$

A.

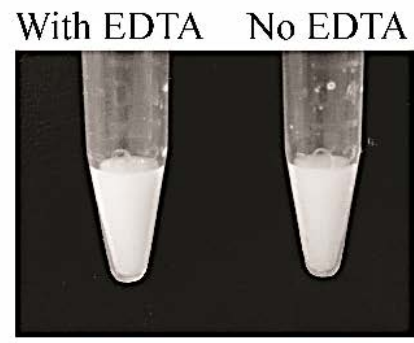

B.

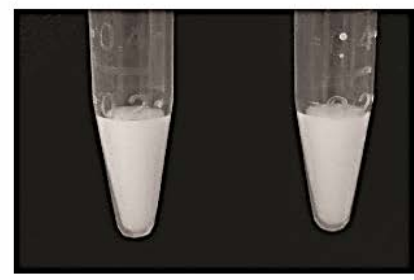

$\mathrm{t}=20$ mins
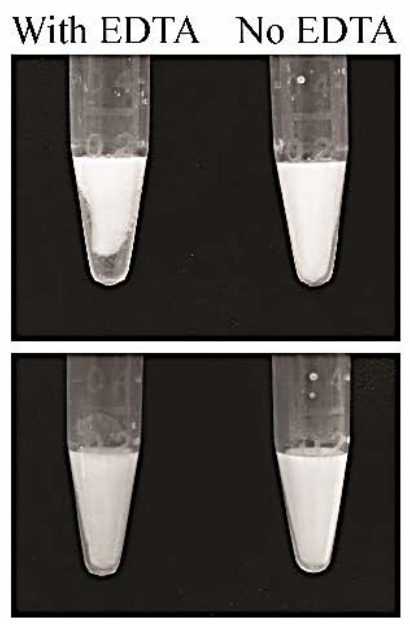

$\mathrm{t}=6 \mathrm{hrs}$
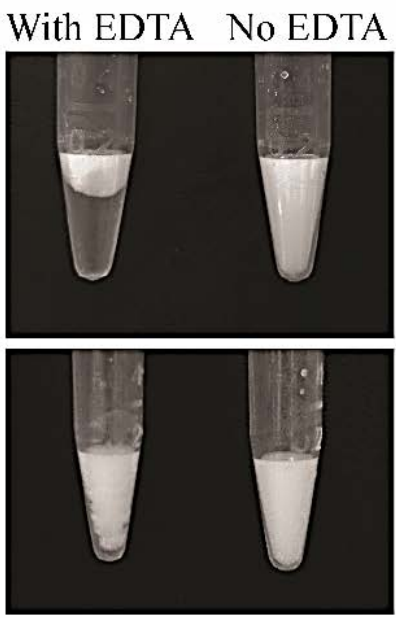

Figure 9. Photographs showing coalescence of $\mathrm{Zn}^{2+}$-peptide-stabilized nanoemulsions by addition of a metal-chelating agent EDTA. Nanoemulsions were prepared using $400 \mu \mathrm{M}$ peptides (A) AM-S and (B) $\mathrm{C}_{8}$-AM in the presence of $800 \mu \mathrm{M} \mathrm{ZnCl}_{2}$.

\section{CONCLUSIONS}

Two peptides, AM-S and $\mathrm{C}_{8}$-AM, were designed incorporating an $\alpha$-helical peptide surfactant (AM1) and additional hydrophobic module, aiming to enhance their function in stabilizing nanoemulsions. In order to study their properties, the peptides' structure in bulk solution, their surface activities at oil-water interface and their performance in preparing and stabilizing nanoemulsions were investigated. The CD spectra revealed the structural differences between AM-S and $\mathrm{C}_{8}-\mathrm{AM}$ in bulk solution, as AM-S has a random coil conformation while $\mathrm{C}_{8}-\mathrm{AM}$ self-assembles into an $\alpha$-helix. The DSA results suggested that the self-assembly of AM-S occurs at the interface, and both peptides showed excellent surface activities with the ability to rapidly adsorb at oil-water interface and reduce the interfacial tension to low equilibrium value (17.0 mN/m for AM-S and $8.4 \mathrm{mN} / \mathrm{m}$ for C-AM). The formation of metal ion $\left(\mathrm{Zn}^{2+}\right)$ mediated intermolecular crosslink was confirmed by visually observing the wrinkled interfacial film in the contraction experiments. Then, the emulsification capability of peptides AM-S and $\mathrm{C}_{8}$-AM 
were demonstrated that both peptides are able to prepare nanoemulsions with small average size (Z-average diameter around 150-200 nm) and good monodispersity ( $\sim 0.20)$. The stability studies found that $400 \mu \mathrm{M}$ AM-S and $100 \mu \mathrm{M} \mathrm{C}_{8}$-AM are sufficient to effectively stabilize prepared nanoemulsions for up to 21 days. At last, the reversibility test showed that the peptidemetal ion $\left(\mathrm{Zn}^{2+}\right)$ crosslink can be actively disrupted, leading to the phase separation of nanoemulsions over time. The result also revealed the important role of the peptide-metal ion $\left(\mathrm{Zn}^{2+}\right)$ interaction in enhancing the stability of prepared nanoemulsions. Noticeably, while apparent phase separation occurred in $400 \mu \mathrm{M}$ AM-S nanoemulsions after 20 minutes of the additional EDTA, $400 \mu \mathrm{M} \mathrm{C}_{8}$-AM nanoemulsions were gradually destabilized over 6 hours before coalescence was observed. Overall, comparing to AM-S, C8-AM exhibited superior surface activity with faster adsorption kinetic and ultralow equilibrium interfacial tension at high concentration. Nanoemulsions prepared using $\mathrm{C}_{8}$-AM exhibited a better stability against coalescence and in the condition of additional EDTA. In contrast, AM-S responded to the metal ion stimuli more effectively then $\mathrm{C}_{8}$-AM. It will be highly valuable to reveal how the individual peptide-surfactant molecules organize at the interface and that the solution compositions influence those interfacial arrangement and packing density of the peptides. For such purposes, neutron reflection ${ }^{25,53}$ in combination with molecular dynamics simulations ${ }^{49,54}$ will be employed in future to investigate the structural properties of the interfacially assembled peptide layer. This work provides useful information for the future design of peptide surfactants, and deepens our understanding of the link between peptide sequence, structure and function.

\section{ASSOCIATED CONTENT}

The methods and results of reversed-phase high-performance liquid chromatography (RPHPLC) and liquid chromatography-mass spectrometry (LC-MS) analyses for peptides AM-S 
and $\mathrm{C}_{8}$-AM, as well as Figures S1-S4 are included in the Supporting Information. This material is available free of charge via the Internet at http://pubs.acs.org.

\section{AUTHOR INFORMATION}

\section{Corresponding Author}

*Phone: +61-7-3346-4263; e-mail z.chunxia@uq.edu.au (C.-X.Z).

\section{Author Contributions}

The manuscript was written through contributions of all authors. All authors have given approval to the final version of the manuscript.

\section{Notes}

The authors declare no competing financial interest.

\section{ACKNOWLEDGMENTS}

This work was supported by the Australian Research Council under Discovery Project (DP150100798) and a Future Fellowship Project (FT140100726). C.-X.Z. acknowledges financial support from the award of the ARC Future Fellowship (FT140100726).

\section{ABBREVIATIONS}

A, alanine; D, aspartic acid; E, glutamic acid; G, glycine; H, histidine; K, lysine; L, leucine; $\mathrm{M}$, methionine; P, proline; Q, glutamine; R, arginine; S, serine; V, valine; Y, tyrosine; $\mathrm{CD}$, circular dichroism; Da, Dalton; DLS, dynamic light scattering; EDTA, ethylenediaminetetraacetic acid; HEPES, sodium 4-(2-hydroxyethyl)-1-piperazine ethanesulfonate; $M$, molecular mass; $Đ$, polydispersity index; RP-HPLC, reversed-phase high-performance liquid chromatography; UV, ultraviolet; v/v, volume-to-volume ratio. 


\section{REFERENCES}

(1) Mulligan, C. N. Environmental Applications for Biosurfactants. Environ. Pollut. 2005, 133, 183-198.

(2) Brokx, R. D.; Bisland, S. K.; Gariépy, J. Designing Peptide-Based Scaffolds as Drug Delivery Vehicles. J. Control. Release 2002, 78, 115-123.

(3) Gelain, F.; Bottai, D.; Vescovi, A.; Zhang, S. Designer Self-Assembling Peptide Nanofiber Scaffolds for Adult Mouse Neural Stem Cell 3-Dimensional Cultures. PLoS One 2006, 1 , e119.

(4) Gelain, F.; Horii, A.; Zhang, S. Designer Self-Assembling Peptide Scaffolds for 3-D Tissue Cell Cultures and Regenerative Medicine. Macromol. Biosci. 2007, 7, 544-551.

(5) Tao, H.; Lee, S. C.; Moeller, A.; Roy, R. S.; Siu, F. Y.; Zimmermann, J.; Stevens, R. C.; Potter, C. S.; Carragher, B.; Zhang, Q. Engineered Nanostructured $\beta$-Sheet Peptides Protect Membrane Proteins. Nat. Meth. 2013, 10, 759-761.

(6) Zelezetsky, I.; Tossi, A. Alpha-Helical Antimicrobial Peptides-Using a Sequence Template to Guide Structure-Activity Relationship Studies. Biochim. Biophys. Acta, Biomembr. 2006, 1758, 1436-1449.

(7) Castelletto, V.; Cheng, G.; Greenland, B. W.; Hamley, I. W.; Harris, P. J. Tuning the Self-Assembly of the Bioactive Dipeptide L-Carnosine by Incorporation of a Bulky Aromatic Substituent. Langmuir 2011, 27, 2980-2988.

(8) Hu, J.; Chen, C.; Zhang, S.; Zhao, X.; Xu, H.; Zhao, X.; Lu, J. R. Designed Antimicrobial and Antitumor Peptides with High Selectivity. Biomacromolecules 2011, 12, 3839-3843.

(9) Hartgerink, J. D.; Beniash, E.; Stupp, S. I. Self-Assembly and Mineralization of Peptide-Amphiphile Nanofibers. Science 2001, 294, 1684-1688. 
(10) Aggeli, A.; Nyrkova, I.; Bell, M.; Harding, R.; Carrick, L.; McLeish, T.; Semenov, A.; Boden, N. Hierarchical Self-Assembly of Chiral Rod-Like Molecules as a Model for Peptide ß-Sheet Tapes, Ribbons, Fibrils, and Fibers. Proc. Natl. Acad. Sci. U. S. A. 2001, 98, 1185711862.

(11) Zhang, S.; Holmes, T.; Lockshin, C.; Rich, A. Spontaneous Assembly of a SelfComplementary Oligopeptide to Form a Stable Macroscopic Membrane. Proc. Natl. Acad. Sci. U. S. A. 1993, 90, 3334-3338.

(12) Zhang, S.; Holmes, T. C.; DiPersio, C. M.; Hynes, R. O.; Su, X.; Rich, A. SelfComplementary Oligopeptide Matrices Support Mammalian Cell Attachment. Biomaterials 1995, 16, 1385-1393.

(13) Barclay, T. G.; Constantopoulos, K.; Matisons, J. Nanotubes Self-Assembled from Amphiphilic Molecules Via Helical Intermediates. Chem. Rev. 2014, 114, 10217-10291.

(14) Egelman, E. H.; Xu, C.; DiMaio, F.; Magnotti, E.; Modlin, C.; Yu, X.; Wright, E.; Baker, D.; Conticello, V. P. Structural Plasticity of Helical Nanotubes Based on Coiled-Coil Assemblies. Structure 2015, 23, 280-289.

(15) Baumann, M. K.; Textor, M.; Reimhult, E. Understanding Self-Assembled Amphiphilic Peptide Supramolecular Structures from Primary Structure Helix Propensity. Langmuir 2008, 24, 7645-7647.

(16) Matsumoto, K.; Vaughn, M.; Bruce, B. D.; Koutsopoulos, S.; Zhang, S. Designer Peptide Surfactants Stabilize Functional Photosystem-I Membrane Complex in Aqueous Solution for Extended Time. J. Phys. Chem. B 2009, 113, 75-83.

(17) Zhao, X.; Nagai, Y.; Reeves, P. J.; Kiley, P.; Khorana, H. G.; Zhang, S. Designer Short Peptide Surfactants Stabilize G Protein-Coupled Receptor Bovine Rhodopsin. Proc. Natl. Acad. Sci. U. S. A. 2006, 103, 17707-17712. 
(18) Bai, S.; Pappas, C.; Debnath, S.; Frederix, P. W. J. M.; Leckie, J.; Fleming, S.; Ulijn, R. V. Stable Emulsions Formed by Self-Assembly of Interfacial Networks of Dipeptide Derivatives. ACS Nano 2014, 8, 7005-7013.

(19) Scott, G. G.; McKnight, P. J.; Tuttle, T.; Ulijn, R. V. Tripeptide Emulsifiers. Adv. Mater. 2016, 28, 1381-1386.

(20) Dexter, A. F.; Malcolm, A. S.; Middelberg, A. P. J. Reversible Active Switching of the Mechanical Properties of a Peptide Film at a Fluid-Fluid Interface. Nat. Mater. 2006, 5, 502506.

(21) Dexter, A. F.; Middelberg, A. P. Switchable Peptide Surfactants with Designed Metal Binding Capacity. J. Phys. Chem. C 2007, 111, 10484-10492.

(22) Malcolm, A. S.; Dexter, A. F.; Katakdhond, J. A.; Karakashev, S. I.; Nguyen, A. V.; Middelberg, A. P. J. Tuneable Control of Interfacial Rheology and Emulsion Coalescence. ChemPhysChem 2009, 10, 778-781.

(23) Chuan, Y. P.; Zeng, B. Y.; O’Sullivan, B.; Thomas, R.; Middelberg, A. P. J. CoDelivery of Antigen and a Lipophilic Anti-Inflammatory Drug to Cells Via a Tailorable Nanocarrier Emulsion. J. Colloid Interface Sci. 2012, 368, 616-624.

(24) Hui, Y.; Wibowo, D.; Zhao, C.-X. Insights into the Role of Biomineralizing Peptide Surfactants on Making Nanoemulsion-Templated Silica Nanocapsules. Langmuir 2016, 32, 822-830.

(25) Middelberg, A. P. J.; He, L.; Dexter, A. F.; Shen, H.-H.; Holt, S. A.; Thomas, R. K. The Interfacial Structure and Young's Modulus of Peptide Films Having Switchable Mechanical Properties. J. R. Soc. Interface 2008, 5, 47-54.

(26) Malcolm, A. S.; Dexter, A. F.; Middelberg, A. P. J. Foaming Properties of a Peptide Designed to Form Stimuli-Responsive Interfacial Films. Soft Matter 2006, 2, 1057-1066. 
(27) Zeng, B. J.; Chuan, Y. P.; O'Sullivan, B.; Caminschi, I.; Lahoud, M. H.; Thomas, R.; Middelberg, A. P. J. Receptor-Specific Delivery of Protein Antigen to Dendritic Cells by a Nanoemulsion Formed Using Top-Down Non-Covalent Click Self-Assembly. Small 2013, 9, 3736-3742.

(28) Pain, R. In Current Protocols in Protein Science; Coligan, J. E., Hidde, L., Ploegh, B. M. D., Speicher, D. W., Wingfield, P. T., Taylor, S. E. G., Eds.; John Wiley \& Sons: New York, NY, 2005; pp 7.6.1-7.6.24.

(29) Pace, C. N.; Scholtz, J. M. A Helix Propensity Scale Based on Experimental Studies of Peptides and Proteins. Biophys. J. 1998, 75, 422-427.

(30) Middelberg, A. P. J.; Dimitrijev-Dwyer, M. A Designed Biosurfactant Protein for Switchable Foam Control. ChemPhysChem 2011, 12, 1426-1429.

(31) Zhang, J.; Hao, R.; Huang, L.; Yao, J.; Chen, X.; Shao, Z. Self-Assembly of a Peptide Amphiphile Based on Hydrolysed Bombyx mori Silk Fibroin. Chem. Commun. 2011, 47, 10296-10298.

(32) Zhou, C.-Z.; Confalonieri, F.; Jacquet, M.; Perasso, R.; Li, Z.-G.; Janin, J. Silk Fibroin: Structural Implications of a Remarkable Amino Acid Sequence. Proteins: Struct., Funct., Bioinf. 2001, 44, 119-122.

(33) Zhao, J.; Dai, C.; Ding, Q.; Du, M.; Feng, H.; Wei, Z.; Chen, A.; Zhao, M. The Structure Effect on the Surface and Interfacial Properties of Zwitterionic Sulfobetaine Surfactants for Enhanced Oil Recovery. RSC Adv. 2015, 5, 13993-14001.

(34) Yoshimura, T.; Sakato, A.; Esumi, K. Solution Properties and Emulsification Properties of Amino Acid-Based Gemini Surfactants Derived from Cysteine. J. Oleo Sci. 2013, 62, 579586.

(35) Greenfield, N. J. Using Circular Dichroism Spectra to Estimate Protein Secondary Structure. Nat. Protoc. 2006, 1, 2876-2890. 
(36) Forns, P.; Lauer-Fields, J. L.; Gao, S.; Fields, G. B. Induction of Protein-Like Molecular Architecture by Monoalkyl Hydrocarbon Chains. Biopolymers 2000, 54, 531-546.

(37) Cohen, C.; Parry, D. A. D. $\alpha$-Helical Coiled Coils and Bundles: How to Design an $\alpha-$ Helical Protein. Proteins: Struct., Funct., Bioinf. 1990, 7, 1-15.

(38) Kohn, W. D.; Hodges, R. S. De Novo Design of $\alpha$-Helical Coiled Coils and Bundles: Models for the Development of Protein-Design Principles. Trends Biotechnol. 1998, 16, 379389.

(39) Dexter, A. F.; Middelberg, A. P. Peptides as Functional Surfactants. Ind. Eng. Chem. Res. 2008, 47, 6391-6398.

(40) Fairman, R.; Chao, H.-G.; Mueller, L.; Lavoie, T. B.; Shen, L.; Novotny, J.; Matsueda, G. R. Characterization of a New Four-Chain Coiled-Coil: Influence of Chain Length on Stability. Protein Sci. 1995, 4, 1457-1469.

(41) Middelberg, A. P. J.; Radke, C. J.; Blanch, H. W. Peptide Interfacial Adsorption is Kinetically Limited by the Thermodynamic Stability of Self Association. Proc. Natl. Acad. Sci. U. S. A. 2000, 97, 5054-5059.

(42) Jena, S.; Das, H. Modeling of Particle Size Distribution of Sonicated Coconut Milk Emulsion: Effect of Emulsifiers and Sonication Time. Food Res. Int. 2006, 39, 606-611.

(43) Lin, C.-Y.; Chen, L.-W. Emulsification Characteristics of Three- and Two-Phase Emulsions Prepared by the Ultrasonic Emulsification Method. Fuel Process. Technol. 2006, 87, 309-317.

(44) Li, P. H.; Chiang, B. H. Process Optimization and Stability of D-Limonene-in-Water Nanoemulsions Prepared by Ultrasonic Emulsification Using Response Surface Methodology. Ultrason. Sonochem. 2012, 19, 192-197.

(45) Leong, T. S.; Wooster, T. J.; Kentish, S. E.; Ashokkumar, M. Minimising Oil Droplet Size Using Ultrasonic Emulsification. Ultrason. Sonochem. 2009, 16, 721-727. 
(46) Dexter, A. F. Interfacial and Emulsifying Properties of Designed $\beta$-Strand Peptides. Langmuir 2010, 26, 17997-18007.

(47) Honary, S.; Zahir, F. Effect of Zeta Potential on the Properties of Nano-Drug Delivery Systems - A Review (Part 2). Trop. J. Pharm. Res. 12, 265-273.

(48) Jacobs, C.; Kayser, O.; Muller, R. H. Nanosuspensions as a New Approach for the Formulation for the Poorly Soluble Drug Tarazepide. Int. J. Pharm. 2000, 196, 161-164.

(49) Mondal, S.; Varenik, M.; Bloch, D. N.; Atsmon-Raz, Y.; Jacoby, G.; AdlerAbramovich, L.; Shimon, L. J.; Beck, R.; Miller, Y.; Regev, O. A Minimal Length Rigid Helical Peptide Motif Allows Rational Design of Modular Surfactants. Nat. Commun. 2017, 8, 14018.

(50) Qian, C.; Decker, E. A.; Xiao, H.; McClements, D. J. Physical and Chemical Stability of $\beta$-Carotene-Enriched Nanoemulsions: Influence of $\mathrm{pH}$, Ionic Strength, Temperature, and Emulsifier Type. Food Chem. 2012, 132, 1221-1229.

(51) Delmas, T.; Piraux, H.; Couffin, A.-C.; Texier, I.; Vinet, F.; Poulin, P.; Cates, M. E.; Bibette, J. How To Prepare and Stabilize Very Small Nanoemulsions. Langmuir 2011, 27, $1683-1692$.

(52) Toledano, O.; Magdassi, S. Emulsification and Foaming Properties of Hydrophobically Modified Gelatin. J. Colloid Interface Sci. 1998, 200, 235-240.

(53) Campana, M.; Hosking, S.; Petkov, J.; Tucker, I.; Webster, J.; Zarbakhsh, A.; Lu, J. R. Adsorption of Bovine Serum Albumin (BSA) at the Oil/Water Interface: A Neutron Reflection Study. Langmuir 2015, 31, 5614-5622.

(54) Xue, Y.; He, L.; Middelberg, A. P. J.; Mark, A. E.; Poger, D. Determining the Structure of Interfacial Peptide Films: Comparing Neutron Reflectometry and Molecular Dynamics Simulations. Langmuir 2014, 30, 10080-10089. 
TABLE OF CONTENTS (TOC) GRAPHIC

Stable

$\mathrm{O} / \mathrm{W}$ nanoemulsions (20 days)
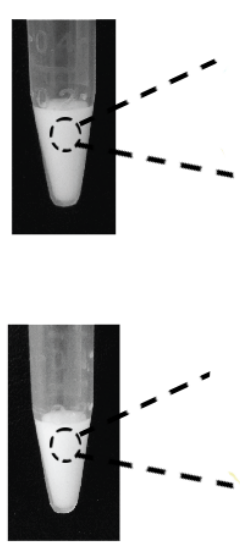

Oil-Water

interface

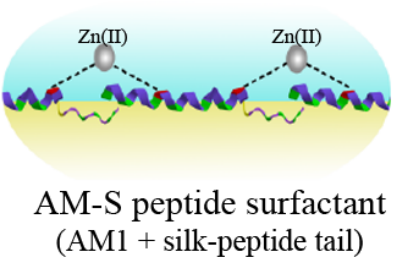

(AM1 + silk-peptide tail)

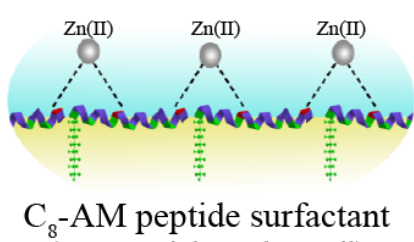

(AM1 + eight-carbon tail)
Added

Chelating agent

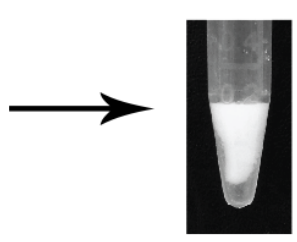

Unstable

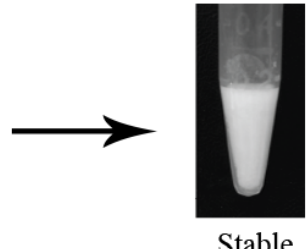

